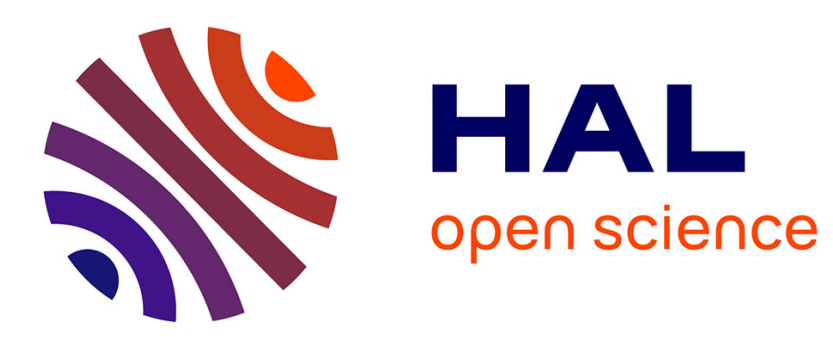

\title{
Corruption as Betrayal: Experimental Evidence on Corruption Under Delegation
}

\author{
Nicolas Jacquemet
}

\section{To cite this version:}

Nicolas Jacquemet. Corruption as Betrayal: Experimental Evidence on Corruption Under Delegation. 2005. halshs-00180044

\section{HAL Id: halshs-00180044 https://shs.hal.science/halshs-00180044}

Preprint submitted on 17 Oct 2007

HAL is a multi-disciplinary open access archive for the deposit and dissemination of scientific research documents, whether they are published or not. The documents may come from teaching and research institutions in France or abroad, or from public or private research centers.
L'archive ouverte pluridisciplinaire HAL, est destinée au dépôt et à la diffusion de documents scientifiques de niveau recherche, publiés ou non, émanant des établissements d'enseignement et de recherche français ou étrangers, des laboratoires publics ou privés. 


\section{Corruption as Betrayal : Experimental Evidence on Corruption Under Delegation}

Nicolas Jacquemet

Juin 2005

GATE Groupe d'Analyse et de Théorie Économique

UMR 5824 du CNRS

93 chemin des Mouilles - 69130 Écully - France

B.P. $167-69131$ Écully Cedex

Tél. +33 (0)4 72866060 - Fax +33 (0)4 72866090

Messagerie électronique gate@gate.cnrs.fr

Serveur Web : www.gate.cnrs.fr 


\title{
Corruption as Betrayal : Experimental Evidence on Corruption Under Delegation *
}

\author{
Nicolas Jacquemet ${ }^{\dagger}$

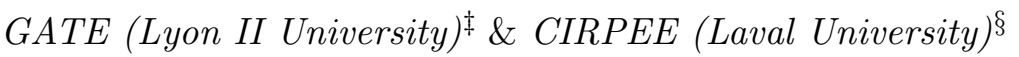

June 2005

\begin{abstract}
We consider corruption behavior in a three-players game : Principal, Agent, Corrupter. When the Principal chooses a fair wage, the Agent faces conflicting interests to reciprocate. This delegation effect is expected to lower the level of corruption as compared to what arises in two-players settings. We set up two experiments varying in the exogeneity of the delegation relationship. The experimental evidence supports the delegation effect. This, in turn, could account for the deterrence effect of wage on corruption even in the absence of detection.
\end{abstract}

Keywords: Corruption, Reciprocity, Enforcement, Principal-Agents relationship.

JEL codes: K49, K12, C91, C72.

${ }^{*}$ An older version of the paper previously circulated as "How Wages Affect Corruption Behavior : an Experimental Investigation of Delegation Consequences". I wish to thank J.L. Rullière, M.C. Villeval, A. Chaudhuri, P. González, B. Sinclair-Desgagné, S. Robin, B. Deffains, K. Abbink and all participants to the 2002 International ESA meeting in Boston, the 2003 Canadian Society of Economics meeting in Montréal and the 2004 Spring Meeting of Young Economists in Warsaw for their remarks on a previous version of the paper. R. Zeileiger is gratefully acknowledged for the software design. Any remaining errors are due to my own limits.

${ }^{\dagger}$ email : nicolas.jacquemet@ecn.ulaval.ca

${ }^{\ddagger}$ GATE: Lyon II University and ENS-LSH, UMR 5824 CNRS; 93 Ch. des mouilles, 69131 Ecully, France.

${ }^{\S}$ CIRPEE: Département d'économique, Université Laval, Québec (Qc) G1K 7P4 Canada. 


\section{Introduction}

Summarizing a rather consensual conception, Jain (2001) defines corruption as the misuse of a delegated power aimed at offering rents to identifiable groups. Given that real economic life widely resorts to delegation, the reasons why corruption attracts more and more attention should be apparent. In fact, one could wonder why corruption is not more widespread given that delegation generally involves diverging interests. Of course, economic theory has already partly answered this question through contract theory and through Becker's seminal work on crime and punishment, in 1968. Although it explains why most of the economic agreements succeed in reconciling diverging interests, the mixed results obtained by anti-corruption programs (Steves and Rousso, 2003) strongly suggest that understanding the determinants of corruption behavior largely remains an open question. In this paper, we derive some determinants of corruption behavior from the conditions governing the delegation.

Among the recent literature on corruption, few studies have focused on corruption behavior itself. Reciprocity, however, is recognized as a key feature of corruption contracts. Due to its illegality, corruption cannot be enforced by third parties (Boycko, Shleifer and Vishny, 1996). Reciprocity between the briber and the person being offered the bribe is thus expected to help corruption contracts being prevented from an ex post renegotiation.

The enforcement power of reciprocity is quite well recognized in economics. Fehr, Gachter and Kirchsteiger (1997) show that reciprocity substantially increases the set of enforceable contracts. In a setting with which our corruption game shares common features, Clark and Sefton (2001) conclude that cooperation can be reached as a result of reciprocity rather than altruism. Corruption, however, is different enough from legal contracts to cast doubt on the direct transposition of these results. To give an example, corruption is this special contract where punishment applies only to the agents who were trustworthy : a person who receives a bribe does not incur legal sanctions if the behavior expected by the briber is not subsequently adopted. Despite this specificity, the enforcement of corruption through reciprocity is generally borne out by experimental evidence (Abbink, Irlenbusch and Renner, 2002) even in one-shot games (Abbink, 2004).

Since the implementation of corruption relies partly on reciprocity, the organizational design from which the agent inherits (and potentially misuses) discretionary power is crucial. Indeed, 
several studies have highlighted the gift exchange involved in delegation relationships, starting with Akerlof's (1982) well-known analysis. More recently, Fehr, Kirchsteiger and Riedl (1993) observed that experimental firms systematically pay workers more than the competitive equilibrium wage. Experimental workers then reciprocate by an increased effort. As a result, the wage associated with delegation is a way to establish a reciprocal relationship with the agent.1

Consider a delegation relationship relying on gift exchange. There is room for corruption if their exists a "briber" with who the principal experiences conflicting monetary interests. In this setting, corruption appears as a decision driven by diverging incentives to reciprocate: corruption implies a conflict in reciprocity because the agent cannot reciprocate to both the briber's and the principal's fairness. This paper focuses on this delegation effect as a determinant of corruption behavior. In addition, the principal's fairness manifests itself through the wage offered to the agent. The higher the wage, the stronger the conflict in reciprocity therefore experienced when a bribe is offered. The delegation effect therefore provides microeconomic support for a negative correlation between wage and corruption.2

Despite its empirical robustness, the effect of wage on corruption has received quite few theoretical support. Yet, the main one is the indirect effect of wage through the risk associated with illegal activities. If a corrupted worker is fired when detected, wages represent the opportunity cost of corruption (Becker and Stigler, 1974). There are, however, various countries and/or contexts for which the effectiveness of detection is doubtful, either because of deficient law enforcement ${ }^{\frac{3}{3}}$ or due to the fact that corruption is simply ignored ${ }^{4}$.

In the absence of any risk of detection, only the direct effects of wage on corruption behavior remain into consideration. On the one hand, dishonest agents may exhibit lower reservation

\footnotetext{
${ }^{1}$ Akerlof and Yellen (1990) provide a review of the empirical relevance of this kind of incentive.

${ }^{2}$ Kaufmann (1997), Ades and Di Tella (1997), Van Rijckeghem and Weder (2001) document this observation. Di Tella and Schargrodsky (2003) provide a synthetic discussion of the results.

3 Bac (1996), Mookherjee and Png (1995) and Carillo (2000) exhibits several mechanisms through which the enforcement of law is compromised, as surveyed by Marjit and Shi (1998). One should recognize those mechanisms in the failing of anti-corruption programs where corruption is too widespread, as shown in Steves and Rousso (2003).

${ }^{4}$ As an example, no university teacher is supervised to prevent a student's bribing for better scholastic results. This possibility should however be taken into account in society's designing of the delegation of education to teachers since diplomas are consequently devalued.
} 
wage since they can expect to increase their on-the-job utility thanks to corruption. Low wages thus attract dishonest agents, and raising wages attracts more and more honest ones (Besley and McLaren, 1993). This explanation stems to a large extent from the assumption that agents are either corruptible or not: if an agent is supposed to be non-corruptible, there is no level of bribe that would make him enter into a corruption contract. We highlight here, a mechanism by which corruptibility results only from the incentives offered. In particular, each agent might be corrupt or not, depending on the delegation relationships he faces.

On the other hand, the relative wage is sometimes supposed to determine the moral cost of corruption through equity considerations. In this way of seeing things, corruption is more likely to occur when the wage is perceived to be unfair in comparison with what employees in another sector get. Relatively well-paid workers should then be less corruptible. Although convincing, this equity hypothesis does not seem to be empirically relevant. Abbink (2002) studies corruption behavior of experimental subjects as regards to this equity feelings. Beyond the subjects playing a corruption game, the experiment also involves some workers asked to perform a given task not related to corruption. All subjects are paid a fixed wage, exogenously determined. In this experiment, corruption behavior do not seem to react to the variations implemented in the wage earned by the external workers. This results cast doubt on the role played by equity in corruption behavior.

In this paper, we highlight the conflict in reciprocity an agent may experience when facing corruption opportunities. To this matter, we develop a corruption game that relies on the interaction between three players. ${ }^{[5}$ The room for corruption stems from the two features described above. On the one hand, the agent inherits delegated power from a principal. Since the accuracy of the decision cannot be evaluated perfectly by the principal, this power may be embezzled for personal gain. Indeed, on the other hand, the briber do wants to lead the agent to such a misuse, due to diverging interests with the principal. Our purpose focuses on the impact of delegation

\footnotetext{
${ }^{5}$ This feature has been well recognized since the earliest work on corruption such that of Banfield (1975) or Rose-Ackerman $(1975,1978)$.
} 
on corruption behavior. In particular, this leads us to keep the link between corruption and delegation design free from the indirect effects of punishment.

The typical case of corruption we want to adress is the well-known licensing example. Here, a public official is asked by the State to select a firm. The State wants the best productive firm to be selected and the expected profit of a particular firm depends on their being granted the license. The principal (State) and the briber (any firm that do not deserve a license) hence experience diverging interests. This open the doors for corruption. If the public official has no particular preference over the selected firm, he may accept the bribe and choose the firm offering it. Alternatively, he may be made sufficiently conscientious by the administration hierarchy to reject the proposal and pick out the most productive firm. Of course, he cannot choose both. The public official's decision will thus lead him to betray either the State or the corrupt firm.

Those features form the basis of our experimental design. More precisely, we set up two experiments, each of which are conducted under various conditions. In the first experiment, a player (agent) receives an exogenously fixed wage for taking a costly decision. Before he makes the decision, he can accept a monetary transfer proposed by a second player (briber), whose payoffs are influenced by the decision. In the second experiment, a stage is added (before this two-players corruption-game) whereby a third player (principal) decides on the wage owned by the first player. Inter experiment comparisons thus highlight the effect of delegation on corruption. For each experiment, we also perform various treatments, each differing in the level of wage. The marginal effect of wage raises on corruption can then be deduced from intra-experiment comparisons.

Earlier experiments have focused on the implementation of corruption in two-player settings. Abbink, Irlenbusch and Renner (2002) establish the enforcement power of reciprocity in corruption contract implementation. A treatment moreover studies the extent to which corruption behavior is sensitive to social considerations. Social stakes are incorporated by assuming that each corruption contract imposes negative payoffs on all other participants in the experiment. Surprisingly, they find no evidence that this negative externality affect corruption behavior. They

\footnotetext{
${ }^{6}$ Note however that detection is expected to reinforce the potential effect of delegation : both the risk of detection and the opportunity cost stemming from the wage lost should lower the level of corruption. As a result, this assumption should not change our qualitative results.
} 
concluded that campaigns appealing to the conscientiousness of officials might be ineffective. Idiosyncratic determinants of corruptibility such as gender, attitude toward risk or education are examined by Frank and Schulze (2000). Men and students in economics appear to be more corrupt. Those two player settings however fail to find a negative correlation between wage and corruption in the absence of detection (Schulze and Frank, 2003). This is a gap this paper aims to fill.

We first present the three-player corruption game and its theoretical analysis. The experimental design is developed in the second section. The third section presents the experimental procedures. The results put in lights some determinants of corruption behavior, presented in the fourth section. The last section concludes.

\section{Three-players corruption game}

We consider a three player game: Agent (A), Principal (P) and Briber (C). The Agent owns a compensation from the Principal, $w$, for being in charge of a delegated task. Let $e$ denote the privately known effort the Agent devotes to the task at cost $v(e)$. Perfect verifiability of effort would lead to immediate detection of corruption on the part of the Principal. Private knowledge of effort is hence a necessary condition for corruption to occur. This is made by considering a random production function. For every occurrence of the random state of nature, $\epsilon$, the effort determines not only the Principal's payoffs but also the Briber's payoffs, $f_{P}(e, \epsilon)$ and $f_{C}(e, \epsilon)$

respectively. Effort is asssumed to be valuable for both, with: $\frac{\partial f_{P}(e, \epsilon)}{\partial e}>0$ and $\frac{\partial f_{C}(e, \epsilon)}{\partial e}>0$. Principal and Briber however expect different increases in their payoffs according to the effort chosen.

For simplicity, we restrict our attention to three levels of effort: $e=e_{i}, i=0,1,2$ depending on which player is favored by the decision. In the first instance, the Agent, by shirking, satisfies neither the Principal nor the Briber (effort $e_{0}, v\left(e_{0}\right)=0$ ). In the second instance, the Agent can favor one of them, by choosing either a productive effort (effort $e_{1}$ such that $f_{P}\left(e_{1}, \epsilon\right)>$ $\left.f_{C}\left(e_{1}, \epsilon\right), \forall \epsilon\right)$ or a corrupt effort $\left(e_{2}\right.$ such that $\left.f_{P}\left(e_{2}, \epsilon\right)<f_{C}\left(e_{2}, \epsilon\right), \forall \epsilon\right)$.

To induce the Agent to choose $e_{2}$, the Briber may offer a bribe. Let $b$ denote the amount the Briber proposes to the Agent. Obviously, the Agent can always choose honesty by rejecting 
this proposition. We denote by $b_{a}$ a bribe that has been accepted. We suppose that every nonshirking effort induces the same cost for the Agent: $v\left(e_{1}\right)=v\left(e_{2}\right)=c>0 .^{7}$ Formally, this means that when the Agent decides not to shirk, this positive effort only implies different consequences for the two principals, i.e. once a positive effort is exerted, choosing the corrupt or the productive effort determines how the surplus generated is shared between the Principal and the Briber: the corrupt effort only appears as a positive effort shifting from the Principal's interest toward that of the Briber.

One can understand this assumption by thinking back once again to the public official who is responsible for firm licensing. He can either shirk or work. In the case where he works, he either selects the best firm and exerts the productive effort, or accepts a bribe from an inefficient firm and selects it, thereby exerting the corrupt effort. Whatever the decision is, it affects the firm's payoff. For example, the firm cannot produce if the Agent does not grant it a license; faces harder competition if another firm is selected; etc. Finally, when exerting either the productive or the corrupt effort, the Agent has to know the firm's quality and evaluate its rank on the basis of the files he has studied. He has to work this way in both instances : either in order to make a decision based on a firm's real merit; or in order to identify a firm whose performance would not ordinarily deserve the granting of a license, thereby leaving the way open for corruption to occur.

The information structure of the game also reflects this typical corruption context. We consider a sequential game in which :

1. Principal chooses the wage owned by the Agent;

2. A state of nature is randomly selected;

3. After observing the state of nature, Briber offers a bribe;

4. Fully informed of all the preceding, Agent takes the decision.

Note that, unlike the Principal, the Briber is fully aware of the decision of the Agent since the state of nature belongs to his information set. Assuming two possible states of nature, Good or $B a d$, the whole three-player corruption game can thus be represented as shown in Figure 1 .

\footnotetext{
${ }^{7}$ This assumption could easily be relaxed. It ensures that the structure of the game does not impose a distortion in favor of one of the two positive efforts.
} 


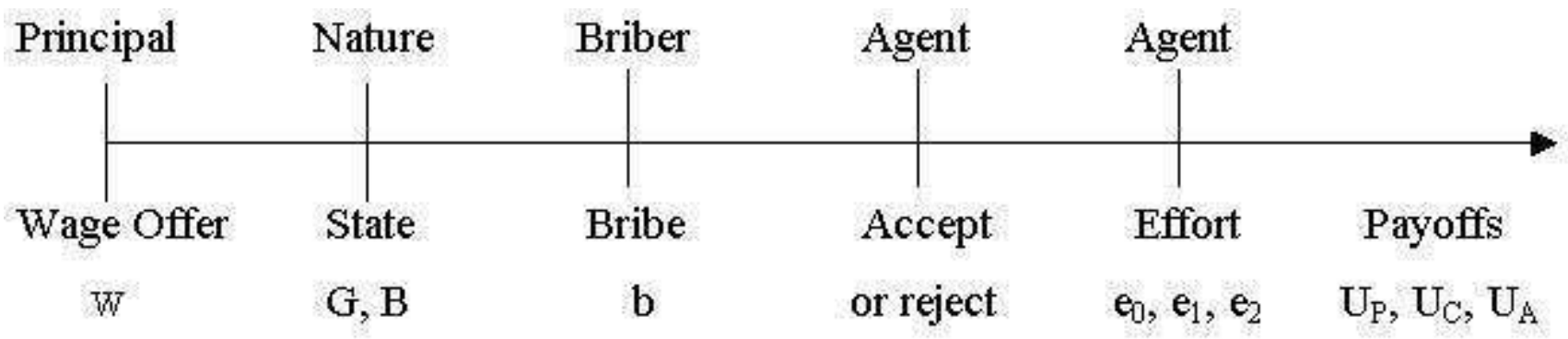

Figure 1: The three-Players CORRuption Game

Denoting respectively by subscript $A, P$ and $C$ the payoff function (U) of the Agent, the Principal and the Briber, the three-player corruption game payments are :

$$
\left\{\begin{array} { l } 
{ U _ { P } = f _ { P } ( e _ { i } , \epsilon ) - w } \\
{ U _ { C } = f _ { C } ( e _ { i } , \epsilon ) - b _ { a } } \\
{ U _ { A } = w + b _ { a } - v ( e _ { i } ) }
\end{array} \quad \text { where } \quad \left\{\begin{array}{l}
v\left(e_{i}\right)=c \forall i=1,2 ; c>0 \\
v\left(e_{0}\right)=0
\end{array}\right.\right.
$$

In this sequential game, the Nash subgame perfect equilibrium is straightforward. Whereas effort is common knowledge for the Agent and the Briber, the corrupt effort cannot be implemented by Briber. In fact, due to its illegality, the Briber is unable to resort to legal proceedings in order to implement an effort $e_{2}$ even if a bribe was given. Thus, for every finite repetition of the game, the Agent always chooses to accept the bribe but to shirk. Applying backward induction, the Briber then never proposes a positive bribe and the Principal chooses the lowest wage acceptable by the Agent.

Proposition 1 The unique Nash subgame perfect equilibrium eliminates bribery and implements shirking behavior.

This theoretical conclusion is classical in the experimental literature on corruption. In particular, Abbink, Irlenbusch and Renner (2002) also obtain such a theoretical prediction within a two-players framework - related to the present corruption game. However, their various experiments (Abbink, Irlenbusch and Renner, 2002 ; Abbink, 2002) show that reciprocity is able to implement corruption, even in one-shot contracts (Abbink, 2004). Those results serves as a benchmark in our study. We next introduce the three-players game, the comparison with which highlights the effect of delegation on corruption. 


\section{Experiment}

We design two experiments. The corruption experiment (CE) eliminates the principal's decision from the game presented above. This benchmark reproduces the previous studies of corruption. To test the impact of delegation on corruption, the second experiment, called explicit delegation experiment (EDE), involves the principal in the corruption relationship. The effect of the contractual relationships between the Agent and the principal on corruption behavior can thus be isolated by comparing the level of corruption between the two experiments. Finally, we conduct each experiment under various treatments. Each treatment differs by the level of wage earned by the Agent. This provide evidence on the effect of wage variations on corruption behavior.

\subsection{Experimental design}

\subsubsection{Corruption Experiment (CE)}

Our first experiment involves only two players : the Agent and the Briber. This experiment thus reflects corruption contracting only. It implements the following three stage game.

In the first stage, the agent is endowed with a fixed wage $\left(W_{H}\right.$, specified below). This wage is common knowledge between the Agent and the Briber. The Agent earns this endowment irrespective of whatever other decisions he makes. The state of nature is then randomly chosen, and immediately announced both to the Briber and to the Agent. Given the production function, the Briber decides whether or not to transfer an amount $b$ of experimental units to the agent.

In the second stage, the Agent has to make two decisions. First, he is asked to accept or reject the proposed transfer. He then chooses an effort level, that is to say one of the three possible efforts : $e_{0}, e_{1}, e_{2}$, called respectively choice $\mathrm{A}, \mathrm{B}$ or $\mathrm{C}$ in the experiment.

Lastly, the Briber and the Agent are informed about all the decisions made. Before starting a new period, each subject is informed about the experimental units earned for the period.

\subsubsection{Explicit Delegation Experiment (EDE)}

In this second experiment, the relationship between the Agent and the Principal is introduced. A preliminary stage is thus added to the Corruption Experiment. In this stage, the principal decides on the wage owned by the agent. 
In order to make clear for participants that this choice can either be selfish or fair, there are two possible wages from which the principal has to choose. The low wage $\left(W_{L}\right)$ is close to the participation wage, thereby making the agent indifferent as to whether shirking or choosing a positive effort. The high wage $\left(W_{H}\right)$ consists of a profit-sharing proposal. The principal's decision is thus given by: $w=\left\{W_{L}, W_{H}\right\} ; W_{L}<W_{H}$.

Before playing the three succeeding stages, corresponding to the Corruption Experiment, the Agent and the Briber are both informed of the Principal's decision. Throughout the experiment, the Principal knows only his own earnings and decision. He is never informed about the agent's behavior.

\subsubsection{Each experiment treatments}

In order to test the impact of wage on corruption, each experiment was conducted with various levels of wages. In a Low High Wage treatment (LHW), the agent's endowment in CE and the high wage in EDE are fixed at $W_{H}=30$. In an Highest Wage treatment $(\mathrm{HW})$, both are fixed to the higher value of $W_{H}=40$. In EDE, the principal chooses between the high wage and a lower level, $W_{L}$. We hence observe corruption under this low wage as often as it is chosen. For ensuring comparability between experiments, $\mathrm{CE}$ is therefore conducted under a third treatment, where wage is fixed to the lowest level $W_{L}$.

The various combinations between experiments and treatments allow us to examine corruption behavior with respect to wage variations within either a two-sided corruption contract or a three-player contractual relationship.

\subsection{Experimental procedure}

The experimental implementation of the game relies on the production function described in Table (1). The agent's disutility of exerting a positive effort is fixed at $c=10$. The lowest wage, taken to be $W_{L}=15$, thus makes the agent almost indifferent as to whether shirking or not. To avoid negative payoffs for Briber, the bribe was limited respectively to 70 or 100 respectively, depending on whether the "bad" or the "good" state of nature occurred. One can easily verify that the surplus created by a positive effort is constant, fixed at 30 whatever the state of nature 
TAble 1: Agent's Production for EACH state of nAture

\begin{tabular}{|c|c|c|}
\cline { 2 - 3 } \multicolumn{1}{c|}{ Effort } & Principal & Briber \\
\hline$e_{0}$ & 70 & 70 \\
\hline$e_{1}$ & 100 & 70 \\
\hline$e_{2}$ & 70 & 100 \\
\hline
\end{tabular}

17a: Good State

\begin{tabular}{|c|c|c|}
\cline { 2 - 3 } \multicolumn{1}{c|}{ Effort } & Principal & Briber \\
\hline$e_{0}$ & 40 & 40 \\
\hline$e_{1}$ & 70 & 40 \\
\hline$e_{2}$ & 40 & 70 \\
\hline
\end{tabular}

$1 \mathrm{~b}:$ Bad State

is. The surplus expected from a corrupt effort is thus far from the upper bounds imposed on the bribe. The results should not be modified, therefore, on the basis of this restriction.

On the Principal's side, this surplus is higher than the increase experienced when switching from the low to the high wage. If the principal expects that a fair wage will ensure the agent's cooperation, it is then in his interest to offer $W_{H}$ under every treatment.

The two experiments were played successively by the same subjects. CE was first played by participants randomly assigned to Briber and Agent role. The role were kept the same during the whole experimental session. The three levels of exogenous wage were played for five rounds each, following the increasing sequence $W_{L}, L H W, H W$. The players exogenously assigned to the role of Principal were placed in a separate room. During CE experiment, they were asked to wait for the beginning of the experiment and made free to surf on the internet. Before EDE experiment started, new instructions were read to each room. At start, the doors separating the room were opened to make clear that the proceedings are common knowledge. The treatments were played five periods each, LHW first and then HW. At the end of the session, participants were asked to answer a questionnaire that provides us various individual characteristics such as gender, studies field, age, etc.

Four experimental sessions were conducted at GATE (Lyon, France), with software developed using Regate (Zeileiger, 2000). Overall, 87 subjects participated to the sessions. Since each three-players group played in partners over the whole twenty-five periods, this provides us 29 independent observations. Participants were first to third-year students in a law, economics or chemistry degree. They earned on average 10 Euros per one hour experiment, which is much higher than the minimum wage in France (slightly less than 6 Euros). The experiment last around one hour and half. 
In order to avoid the "real-life effect", instructions were written using neutral language. ${ }^{8}$ Bribe is referred to as transfer, effort as choice and wage as payoff. Players were called respectively "Participant X" (Agent), "Participant Y" (Briber) and "Participant Z" (Principal). The two states of nature were arbitrarily presented as "left-hand table" $(g)$ and "right-hand table" $(d)$ reflecting the position of the good and bad states of nature in Table 1. The likelihood of each one was fixed to $p=0.5$. The instructions read to Bribers and Agents are reproduced in Appendix B. In order to ensure that instructions were well understood, participants were asked to fill in a questionnaire about the experiment. All answers were publicly commented on before starting.

\section{Some determinants of corruption behavior}

Proposition 1 states that corruption is not an equilibrium of the game we introduce. Previous experimental studies (Abbink, Irlenbush and Renner; 1999) have shown, however, that reciprocity between the Briber and the Agent is able to implement corruption contracts. Our first hypothesis checks the validity of this result in our experiment.

Hypothesis 1 In the Corruption Experiment as in the Explicit Delegation Experiment, significant corruption levels occur thanks to reciprocity.

If reciprocity does support corruption contracts implementation, introducing the delegation relationships may then give rise to a conflict in reciprocity. In case the principal and the Briber both seek for Agent's fairness, the Agent has to betray at least one of them. When the principal uses the wage as an incentive device, this delegation effect should then lower the likelihood of corruption. We formulate our second hypothesis accordingly.

Hypothesis 2 A principal choosing a high wage give rise to a conflict in reciprocity. This delegation effect lowers corruption in the Explicit Delegation Experiment.

Last, remember that the principal relies on the Agent's reciprocity only when choosing a high wage. If a delegation effect influences corruption behavior, the level of corruption should then

\footnotetext{
${ }^{8}$ In fact, the results obtained by Abbink and Hennig-Schmidt (2002) tend to substantiate the fact that the way instructions are written does not alter corruption behavior.
} 
be lower the higher the wage. Since our game do not include any risk of detection, there is no reason for this correlation to appear in the Corruption Experiment.

Hypothesis 3 A higher wage lowers the level of corruption in the Explicit Delegation Experiment through the delegation effect.

The experimental results are analyzed with respect to these three hypotheses ${ }^{9}$

\subsection{Corruption contracts implementation}

The level of corruption is revealed by the number of accepted transfers which successfully manipulated the decision made by the Agent. In each experiment, we hence consider that a corruption contract has been implemented when the bribe offered by the Briber is accepted and leads the Agent to choose the corrupt effort. Despite the optimistic theoretical predictions we provided above, significant corruption does appear in both experiments.

Observation 1 Reciprocity is able to implement corruption contracts even in the Explicit Delegation Experiment.

Support We first provide support to the implementation of corruption contracts.

Table 2: Corruption and Acceptation rates, By treatment

\begin{tabular}{lc||cc} 
Treatment & Wage & Acceptation & Corruption \\
\hline CE & 15 & $73 \%$ & $23 \%$ \\
CE & 30 & $67 \%$ & $30 \%$ \\
CE & 40 & $68 \%$ & $33 \%$ \\
EDE - LHW & 15 & $59 \%$ & $27 \%$ \\
EDE - LHW & 30 & $44 \%$ & $18 \%$ \\
EDE - HW & 15 & $49 \%$ & $14 \%$ \\
EDE - HW & 40 & $51 \%$ & $13 \%$ \\
\hline
\end{tabular}

Table 2 offers an overview of acceptation and corruption behavior under each condition (experiment/treatment combination). Agents frequently accept the transfer proposed, accepting the transfer from $44 \%$ to $73 \%$ of the

\footnotetext{
${ }^{9}$ The raw data are available from the author upon request.
} 
time. This acceptation do not systematically lead to corruption. In fact, Agents are corrupt at most $33 \%$ of the time. Despite the gap between acceptation and corruption, significant corruption occurs. We construct an artificial treatment where corruption is never chosen. Comparing actual behavior to this hypothetical behavior hence provide a test of the extent to which corruption is pregnant in the experiment. Indeed, the hypothesis that behavior is the same as if Agents were always uncorrupt is rejected for all treatment (matched pairs signed-rank test, $1 \%)$.

It seems that Bribers anticipated this success of positive transfers. As shown in the last column in Table 3 . the average transfer offered ranges from 8.46 to 14.06 across conditions. This is a clear deviation from the null transfer predicted by the equilibrium. In fact, the hypothesis that the average transfer is null is rejected for all treatments with at least $95 \%$ confidence (matched pairs signed-rank test).

In the experiments, corruption hence occurs as a result of two deviations from equilibrium. First, the Agent does exert a positive effort in the last period of the game. At the stage before, the Briber moreover offers a positive bribe despite the lack of guarantee for corruption implementation. We now turn to the means by which corruption is implemented between Agent and Briber. Among the various behavioral assumptions proposed in the literature ${ }^{10}$, it seems that reciprocity is the most relevant explanation, confirming previous findings on corruption behavior.

Support On the Agent side, the decision to exert the corrupt effort is positively linked to the transfer proposed.

Table 3: Average transfer on Agent's Behavior, By treatment

\begin{tabular}{lc||cccc} 
Treatment & Wage & Honest & Betray & Corrupt & Overall \\
\hline CE & 15 & 2.66 & 13.72 & 28.14 & 14.06 \\
CE & 30 & 0.26 & 15.06 & 25.26 & 13.33 \\
CE & 40 & 0.38 & 10.25 & 24.66 & 11.89 \\
EDE - LHW & 15.00 & 0.89 & 12.89 & 25.33 & 11.38 \\
EDE - LHW & 30.00 & 0.48 & 14.36 & 30.60 & 9.49 \\
EDE - HW & 15.00 & 0.02 & 8.13 & 29.47 & 6.85 \\
EDE - HW & 40.00 & 0.05 & 13.80 & 24.40 & 8.46 \\
\hline
\end{tabular}

Table 3 summarizes average transfer proposed distinguished upon Agent behavior. In the table, a decision is labeled honest if the Agent refuses the transfer. This decision is mainly associated with very low transfers proposals, ranging from 0.02 to 2.66. A decision is considered as a betrayal when the Agent accepts the transfer

\footnotetext{
${ }^{10}$ Rabin (1998) provides an insightful survey on the subject.
} 
but do not exerts the corrupt effort. The average transfer leading to this decision ranges between 8.13 and 15.06 , hence corresponding to intermediate levels of transfers. Indeed, the highest average transfers are those that lead the Agent to be corrupt : accepting the transfer and exerting the corrupt effort.

This picture is confirmed by the correlation between corruption decisions and the level of transfer proposed, presented in Table 4. All correlations of transfer with corruption and acceptation are positive: a higher bribe increases both the probability of acceptation and the likelihood of corruption. For all treatment but one (Corruption Experiment with a 40 endowment), the correlation is lower for acceptation than for corruption. This reflects the fact that those acceptations that are followed by betrayals are associated with lower transfer proposals. For acceptation as for corruption, the hypothesis that corruption and transfer are independent (i.e. correlation is null) is rejected with highly significant p-values (Spearman correlation test).

Table 4: Spearman correlations with Proposed transfer, By treatment

\begin{tabular}{lc||ccc} 
Treatment & Wage & Corruption & Acceptation & Past Corruption \\
\hline CE & 15 & $0.612^{* * *}$ & $0.595^{* * *}$ & $0.576^{* * *}$ \\
CE & 30 & $0.749^{* * *}$ & $0.596^{* * *}$ & $0.627^{* * *}$ \\
CE & 40 & $0.696^{* * *}$ & $0.719^{* * *}$ & $0.716^{* * *}$ \\
EDE - LHW & 15 & $0.758^{* * *}$ & $0.675^{* * *}$ & $0.469^{* * *}$ \\
EDE - LHW & 30 & $0.832^{* * *}$ & $0.680^{* * *}$ & $0.538^{* * *}$ \\
EDE - HW & 15 & $0.708^{* * *}$ & $0.644^{* * *}$ & $0.569^{* * *}$ \\
EDE - HW & 40 & $0.792^{* * *}$ & $0.486^{* * *}$ & $0.449^{* * *}$ \\
\hline
\end{tabular}

Significance Levels : $*: 10 \% * *: 5 \% * * *: 1 \%$

On the part of Briber, transfer proposals also appears to be responsive to the decisions made by the Agent. The last column in Table 4 provide Spearman rank-order correlations between transfer proposals and corruption decision at the preceding period. A positive correlation hence reflects that Briber's reciprocates to past corruption by offering higher transfer in the next period. For all treatments, correlations are positive and the hypothesis that transfer is independent of last corruption decision is rejected. Our data allows to characterize further the behavior of Briber. In fact, whereas the proposals react to the conditions we implement, we find almost no difference between positive proposals: conditional on being positive, bribery behavior is the same ${ }^{11}$. It then seems that Briber adjust proposals according to a binary strategy (proposing or not) rather than using a continuous adjustment in the level of transfer. This observation is congruent with what Abbink, Irlenbusch and Renner (2002) find in their two-players experiment.

The reciprocity supporting corruption contracts is two sided. The Agent reciprocates to the level of bribe offered by choosing more frequently the corrupt effort after a relatively higher

\footnotetext{
${ }^{11} \mathrm{~A}$ notable exception arise in transfer behavior under EDE 40.
} 
proposal. But the Briber reciprocates two, by proposing a bribe more often when an Agent proved to be compliant.

\subsection{The delegation effect}

Observation 1 establishes the validness of our first hypothesis, aimed at confirming previous results on corruption behavior. As stated in Hypothesis 2, corruption being supported by reciprocity opens the door for a conflict in reciprocity. This lead to a delegation effect, through the relationships settled by the principal. Our experiments support the existence of such a mechanism.

Observation 2 For a given level of wage, the Agent tends to be less likely to be corrupt when the delegation is explicitly involved, due to a conflict in reciprocity.

Support We first present a brief overview of our statistical strategy. The empirical evidence is based on comparisons between the various conditions we observe (i.e. experiment/wage combinations). Since the same individuals are observed under each condition, the tests are based on matched pairs. Tables $[5$ and 6 provide the results of Wilcoxon matched pairs sign-rank tests for comparisons between the various control and treatment conditions indicated in the first two columns. The associated p-values test the null hypothesis that corruption behavior is the same under control and treatment conditions.

For each comparison, the sign of the test indicates whether corruption is higher $(+)$ or lower $(-)$ under control condition than under treatment. The control and treatment are defined in such a way that our hypotheses always predict a decrease in - or, at least, no effect on - corruption while switching from control to treatment conditions. As a result, we always expect the sign of the test to be positive. We hence provide one-sided p-values when the sign of the test is positive and two-sided otherwise.

Last, we stressed earlier that transfer proposals are adjusted by Briber through a binary scheme: positive bribes are more or less frequent but, conditional on being positive, the amount proposed is rather insensitive to conditions. From now on, we are interested in the Agent's behavior induced by a context of diverging incentives to reciprocate. We hence isolate this behavior from variations due to adjustment on the part of the Briber by analyzing Agent's decisions in front of a positive transfer. Further support to our results is proposed thanks to regressions on the decisions variables, presented in Section A. Although they provide a useful guide for the marginal effect of each variable, those regressions should be taken with much precaution. In particular, the estimations do not account for the endogeneity that arises from decision variables (transfer and wage).

The delegation effect is uncovered by comparisons between experiments for a given level of wage. The results are summarized in Table 5. A clear dividing line appears in the result. While corruption is - not significatively 
TABLE 5: INTER-EXPERIMENT COMPARISONS

\begin{tabular}{ll|cl} 
& \multirow{2}{*}{} & \multicolumn{2}{|c}{ Difference } \\
$\mathrm{CE}$ & \multicolumn{1}{c|}{ EDE } & Sign & p-value $\dagger$ \\
\hline 15 & 15 & - & 0.112 \\
30 & LHW -30 & + & $0.096^{*}$ \\
40 & HW -40 & + & $0.008^{* * *}$ \\
\hline \multicolumn{3}{l}{ Levels : $*: 10 \% * *: 5 \% * * *: 1 \%$}
\end{tabular}

- higher under CE than under EDE when wage is the lowest, it decreases between CE and EDE when wage is higher. For the both high wages, the signs are positive and the null hypothesis that behavior is the same under $\mathrm{CE}$ as under EDE is rejected with at least $95 \%$ confidence.

We expect a delegation effect to arise as a result of a conflict in reciprocity experienced by the Agent. A necessary condition for this effect to be effective is then that a reciprocity relationships is established by the Principal. That's what we observe in the experiment. Indeed, the data provide evidence of a significant decrease in corruption due to delegation when, and only when, the Principal chooses the highest available wage. We conclude that the delegation effect do explains corruption behavior. This delegation effect stems from the conflict in reciprocity the Agent faces. ${ }^{12}$

Hypothesis 3 was formulated based on the effectiveness of this conflict in reciprocity. The device used by the Principal to establish a reciprocity relationships is the wage chosen. As a result, the level of wage may impact corruption behavior when such a delegation effect exists. Conversely, since this latter effect is absent in the isolated interaction between the Briber and the Agent, wage variations should leave the level of corruption unchanged in this context.

Observation 3 Corruption tends to be increasing in line with wage. The link is reversed by the delegation relationship between the Agent and the Principal.

\footnotetext{
${ }^{12}$ The increase in corruption between $\mathrm{CE}$ and EDE under low wage moreover suggest that not only positive reciprocity but also negative reciprocity is at stake in corruption behavior. Note that low wage in EDE is chosen by the principal instead of an higher wage (either LHW or HW, depending on the treatment considered). This can then be interpreted by the Agent as an unfair behavior, providing incentive for an increase in corruption. Since the null hypothesis of identical behavior under CE and EDE with low wage cannot be clearly rejected by our data, this suggestion should however be taken with precaution.
} 
Support Table 6 provides an overview for intra-experiment comparisons.

\begin{tabular}{cc|cl|cl}
\multicolumn{4}{c}{ TABle 6: InTRA-EXPERIMENT COMPARISONS } \\
Wage & \multicolumn{2}{c}{ CE } & \multicolumn{2}{c}{ EDE } \\
Control & Treatment & Sign & p-value $\dagger$ & Sign & p-value \\
\hline 15 & 30 & - & $0.090^{*}$ & + & $0.056^{*}$ \\
15 & 40 & - & $0.016^{* *}$ & + & $0.034^{* *}$ \\
30 & 40 & - & 0.491 & + & $0.083^{*}$ \\
\hline
\end{tabular}

Significance levels : $*: 10 \% * *: 5 \% * * *: 1 \%$

It then highlights the sensitivity of corruption behavior to the wage earned for a given delegation scheme (anonymous for CE, explicit for EDE). The first column summarizes the result for variations in corruption behavior inside CE. The wage was expected to have no effect. In fact, all signs are negative and they are significant for the first two comparisons. 13 .

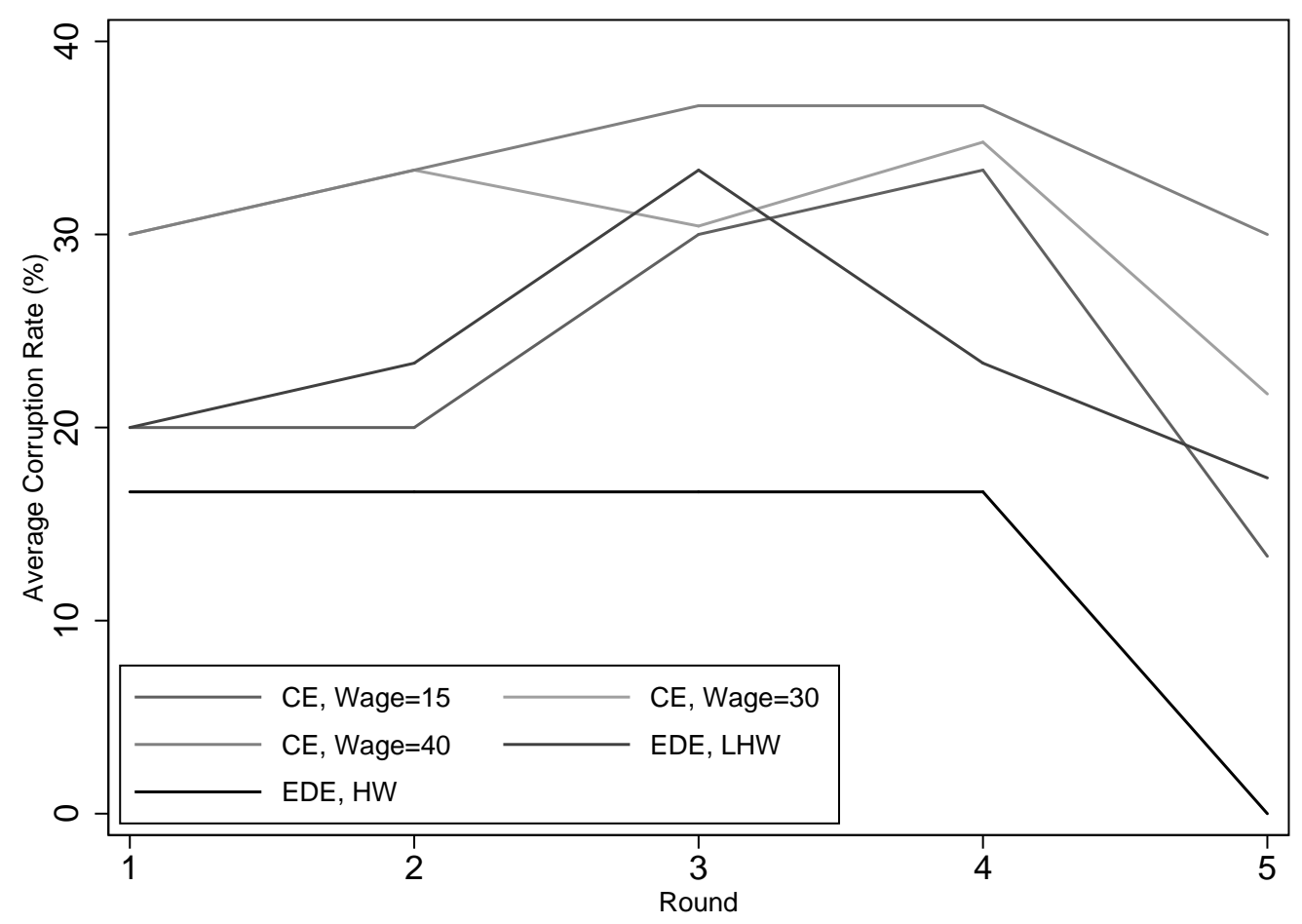

Figure 2: Evolution of CORRuption inside treatments.

${ }^{13}$ This result is confirmed by probit regression in Table 7]: wage on its own tends to increase the probability of being corrupt. 
Since the three treatments were played successively, it could be the case that corruption increases from one treatment to another due to learning. However note that learning should then be at stake not only across treatments but also from one period to another. Figure 2 provides preliminary support against this hypothesis. We draw the average level of corruption for each treatment. The trend patterns are very similar for all conditions, including a strong end-game effect. We moreover perform a test for learning by comparing behavior from period to period inside each condition. For all conditions, the hypothesis that corruption behavior is the same from one period to another cannot be rejected (Wilcoxon signed-rank test). ${ }^{14}$

On the opposite, the tests for corruption sensitivity to wage under delegation all are positive. Corruption hence tends to decrease when the principal offers higher wages and all decreases are significant at less than $10 \%$.

Our corruption game rules out the environments that were recognized to implement a link between corruption behavior and the level of wage (detection, adverse selection, equity...). Thanks to this focus, an original result arises. It seems that the level of wage in fact helps corruption, in the sense that the cost of the corrupt effort is more easily bear by the Agent as wage increases. When this wage is freely chosen by a principal, the delegation effect breaks the link. As wage increases, the conflict in reciprocity the Agents faces is sharper and sharper. As a result, the Agent tends in average to reciprocate less to the Briber proposals, and the level of corruption decreases.

\section{Conclusion}

In a moral hazard setting with fixed wage, we argued that corruption may induce a conflict in reciprocity: the effort chosen may lead the agent to reciprocate to the fairness of one of the two principals. The three-player corruption game features such a mechanism: an agent receives a fixed wage, strategically chosen by the principal. When exerting a positive effort, the agent can either reciprocate to the bribe received from a briber by exerting the corrupt effort, or choose the productive effort the principal expects. Two experiments were conducted with the same subjects, each containing various treatments. The corruption contract was isolated in a Corruption Experiment whereas the three-players game between the principal, the briber and the agent was

\footnotetext{
${ }^{14}$ Once again, those results are confirmed by the probit regression provided in Appendix. Once we control for end game, time has no effect on corruption behavior.
} 
examined in an Explicit Delegation Experiment. In each experiment, the reciprocity relationships between the agent and the briber has been shown to implement corruption. Corruption is lower when an high wage is chosen by a principal. This provides support for the delegation effect. Furthermore, each experiment was run under various levels for the wage earned by the agent. Those treatments provide evidence on the link between wage and corruption. We surprisingly observe an increase in corruption in line with wage. We conjecture that the result stems from the fact that the higher the wage is, the easier the cost of exerting a positive effort is bear. The delegation effect reverses the link due to the fact that the conflict in reciprocity the agent faces is more and more accurate as the wage increases.

These findings have several policy implications. First, the delegation effect relies on a reciprocity relationship established between the principal and the agent. The results could thus explain why corruption is more widespread in public administrations than in private organizations. Indeed, bureaucratic systems rely on impersonal delegation and rather indirect delegation relationships. Those conditions are close to our two-players game, were corruption is easier to implement. Second, since reciprocity is a well recognized device for corruption implementation, it has been recently proposed (Abbink, 2004) to break the trust between the briber and the agent by increasing staff rotation. In fact, this solution has been implemented in several organizations, such as banks, where corruption is seen as a potential problem. Corruption behavior in the Explicit Delegation Experiment shows, however, that this incentive to honesty could be countervailing. In fact, breaking the reciprocity relationship between the agent and the briber also breaks the relationship between the agent and the principal. It is an open question to know precisely to what extent the delegation relationship is maintained when the agent belongs to the same organization as before, but it is likely that increases in staff turnover lead to less trust in delegation, hence to more corruption.

An interesting avenue for further research would consist of explaining the determinants of the agent's betrayal of the briber's trust. Since corruption cannot be legally enforced, betrayal incentives should become a powerful device for corruption deterrence. 


\section{References}

Abbink K. (2002). Fair Salaries and the Moral Costs of Corruption, CeDEx WP, 2002 (5).

Abbink K. (2004). Staff rotation as an anti-corruption policy: an experimental study, European Journal of Political Economy, 20 (4), pp. 887-906.

Abbink K.Hennig-Schmidt H. (2002). Neutral versus Loaded Instructions in a Bribery Experiment, Bonn Econ DP, 23/2002.

Abbink K., Irlenbusch B.Renner E. (2002). An Experimental Bribery Game, Journal of Law, Economics, $\&$ Organization, 18 (2), pp. 428-454.

Ades A.Di Tella R. (1997). National Champions and Corruption: Some Unpleasant Interventionist Arithmetic, Economic Journal, 107 (443), pp. 1023-1042.

Akerlof G. A. (1982). Labor Contracts as Partial Gift Exchange, Quarterly Journal of Economics, 97 (4), pp. 543-569.

Akerlof G. A.Yellen J. L. (1990). The Fair Wage-Effort Hypothesis and Unemployment, Quarterly Journal of Economics, 105 (2), pp. 255-283.

Bac M. (1996). Corruption, supervision, and the structure of hierarchies, Journal of Law, Economics, $\&$ Organization, 12 (2), pp. 277-298.

Banfield E. C. (1975). Corruption as a Feature of Governmental Organization, Journal of Law and Economics, 18 (3), pp. 587-605.

Becker G. S. (1968). Crime and Punishment: An Economic Approach, Journal of Political Economy, 76 (2), pp. 169-217.

Becker G. S.Stigler G. J. (1974). Law Enforcement, Malfeasance, and Compensation of Enforcers, Journal of Legal Studies, 3 (1), pp. 1-18.

Besley T.McLaren J. (1993). Taxes and Bribery: The Role of Wage Incentives, Economic Journal, 103 (416), pp. 119-141.

Boycko M., Shleifer A.Vishny R. W. (1996). A Theory of Privatisation, Economic Journal, 106 (435), pp. 309-319. 
Carillo J. D. (2000). Corruption in Hierarchies, Annales d'Economie et de Statistiques, 59, pp. 37-61.

Clark K.Sefton M. (2001). The Sequential Prisoner's Dilemma: Evidence on Reciprocation, Economic Journal, 111 (468), pp. 51-68.

Di Tella R.Schargrodsky E. (2003). Controlling corruption through high wages In T. International (Ed.), Global Corruption Report 2003. 377-379. London: Robin Hodess.

Fehr E., Gachter S.Kirchsteiger G. (1997). Reciprocity as a Contract Enforcement Device: Experimental Evidence, Econometrica, 65 (4), pp. 833-860.

Fehr E., Kirchsteiger G.Riedl A. (1993). Does Fairness Prevent Market Clearing? An Experimental Investigation, Quarterly Journal of Economics, 108 (2), pp. 437-459.

Frank B.Schulze G. G. (2000). Does economics make citizens corrupt?, Journal of Economic Behavior \& Organization, 43 (1), pp. 101-113.

Frank B.Schulze G. G. (2003). Deterrence versus intrinsic motivation: Experimental evidence on the determinants of corruptibility, Economics of Governance, 4 (2), pp. 143-160.

Jain A. K. (2001). Corruption: A Review, Journal of Economic Surveys, 15 (1), pp. 71-121.

Kaufmann D. (1997). Corruption: The facts, Foreign Policy, 107, pp. 114-110.

Marjit S.Shi H. (1998). On controlling crime with corrupt officials, Journal of Economic Behavior $\&$ Organization, 34 (1), pp. 163-172.

Mookherjee D.Png I. P. L. (1995). Corruptible Law Enforcers: How Should They Be Compensated?, Economic Journal, 105 (428), pp. 145-159.

Rabin M. (1998). Psychology and Economics, Journal of Economic Literature, 36 (1), pp. $11-46$

Rose-Ackerman S. (1975). The economics of corruption, Journal of Public Economics, 4 (2), pp. 187-203.

Rose-Ackerman S. (1978). Corruption : a study in political economy. New-York: NewYork Academic Press. 
Steves F.Rousso A. (2003). Anti-corruption programmes in post-communist transition countries and changes in the business environment, 1999-2002, Economics WP Archive at WUSTL, 85.

Van Rijckeghem C.Weder B. (2001). Bureaucratic corruption and the rate of temptation: do wages in the civil service affect corruption, and by how much?, Journal of Development Economics, 65 (2), pp. 307-331.

Zeiliger R. (2000). A presentation of Regate, Internet based Software for Experimental Economics, http://www.gate.cnrs.fr/zeiliger/regate/RegateIntro.ppt, GATE. 


\section{A Appendix: Regression}

TABLE 7: RANDOM EFFECT PROBIT ON CORRUPtION BEHAVIOR

\begin{tabular}{|c|c|c|}
\hline Variable & Coefficient & (Std. Err.) \\
\hline Lagged Corruption & 0.063 & $(0.240)$ \\
\hline Lagged Acceptation & -0.160 & $(0.267)$ \\
\hline Lagged Transfert & -0.010 & $(0.011)$ \\
\hline Proposed transfert & $0.100^{* * *}$ & $(0.010)$ \\
\hline Wage & $0.037^{* * *}$ & $(0.010)$ \\
\hline Wage under delegation & $-0.056^{* * *}$ & $(0.019)$ \\
\hline Right Table & $0.478^{* *}$ & $(0.197)$ \\
\hline Delegation & $1.163^{* *}$ & $(0.481)$ \\
\hline Round (1-5) & 0.034 & $(0.114)$ \\
\hline End game effect & $-0.736^{* *}$ & $(0.329)$ \\
\hline Age & 0.143 & $(0.088)$ \\
\hline Men & -0.248 & $(0.212)$ \\
\hline Intercept & $-5.910^{* * *}$ & $(1.986)$ \\
\hline \multicolumn{3}{|c|}{ Unobserved heterogeneity } \\
\hline$\widehat{\sigma}$ & $-2.669^{* * *}$ & $(1.018)$ \\
\hline
\end{tabular}

\section{B Supplementary material: Rules for the experiment ${ }^{15}$}

You are involved in an experiment in which you can earn money. The amount you will earn depends upon both your own decision and that of the other participants'. All the decisions you have to take and all information you need will be available on the computer assigned to you.

This experiment is split into two phases. The rules for the first phase are described below. At the end of this first phase, new rules will be distributed.

At the beginning of this experiment, groups of two participants (you and one another) are randomly constituted. Each group member is given, at the beginning of the experiment, a different role. This role is either X, or Y. Each participant keeps the same role and belongs to the same group for the whole experiment.

\footnotetext{
${ }^{15}$ Original text in French. For EDE, the two phases were distributed and read as a single game.
} 


\section{RULES FOR THE FIRST PHASE}

The first phase is composed of three parts, each part consisting of five periods.

HOW EACH PERIOD WILL UNFOLD

At the beginning of each period, $\mathrm{X}$ receives an endowment announced to all participants.

At the beginning of each period, the table according to which the period will take place is randomly selected. The table on the left is chosen with a probability of 0.5 , the one on the right, with probability 0.5. $\mathrm{X}$ and $\mathrm{Z}$ know which table was randomly chosen.

\begin{tabular}{|c|c|c|}
\hline X's decision & Cost for X & Y's Payoff \\
\hline A & 0 & 70 \\
\hline B & 10 & 70 \\
\hline C & 10 & 100 \\
\hline
\end{tabular}

\begin{tabular}{|c|c|c|}
\hline X's decision & Cost for X & Y's Payoff \\
\hline A & 0 & 40 \\
\hline B & 10 & 40 \\
\hline C & 10 & 70 \\
\hline
\end{tabular}

\begin{tabular}{|c|c|}
\hline Minimum transfer & 0 \\
\hline Maximum transfer & 100 \\
\hline
\end{tabular}

Left table(g)

\begin{tabular}{|c|c|}
\hline Minimum transfer & 0 \\
\hline Maximum transfer & 70 \\
\hline
\end{tabular}

Right table(d)

During the period, $\mathrm{X}$ chooses between three options : $\mathrm{A}, \mathrm{B}$ or $\mathrm{C}$, which impacts the respective earnings of $\mathrm{X}$ and $\mathrm{Y}$. For instance, if the left table is randomly chosen and $\mathrm{X}$ chooses the option $\mathrm{B}, \mathrm{X}$ bears a cost of 10 units deducted from his earnings for the period and $\mathrm{Y}$ earns 70.

Before this decision, $\mathrm{Y}$ can offer $\mathrm{X}$ a transfer. $\mathrm{X}$ can accept or reject this transfer. In case it is accepted, the transfer is deducted from the earnings of $\mathrm{Y}$ and added to the the earnings of $\mathrm{X}$. The transfer has to be chosen between 0 and 100 when the left table is randomly selected. The transfer has to be chosen between 0 and 70 when the right.

At the end of the period, $\mathrm{Y}$ is informed of the option $\mathrm{X}$ has chosen.

To sum up, each period in the first phase is ongoing according to the following steps :

- 1st Stage: X earns an endowment.

- 2nd Stage: A table is randomly selected according to a 0.5 probability. X and Y are informed of the choice of table and the endowment received by $\mathrm{X}$.

- 3rd Stage: Y offers a transfer to X, between 0 and 100 if the left table was selected and between 0 and 70 if the left table was selected.

- 4th Stage: X accepts or rejects the transfer.

- 5th Stage: X either accepts or rejects this transfer.

- 6th Stage: Y earns the payoff specified by X's decision.

- Y's net payoff equals this payoff minus the proposed transfer if accepted.

- X's net payoff equals the endowment, plus the transfer if accepted, minus the cost of the decision.

At the end of the period, your payoff and your net payoff for the current period appears on the screen. 


\section{HOW EACH PART WILL UNFOLD}

The first phase includes three parts. The only change from one part to another is the amount of the endowment owned by $\mathbf{X}$. This endowment is announced to all participants at the beginning of the first period of each part.

At the end of the five periods, every participant begins a new part. Groups and roles remain the same during the whole three parts.

\section{HOW WILL YOU DECIDE?}

The screen of your computer is split into three areas :

The first one informs you both about your role for the duration of the experiment and about rules which are applicable to the ongoing part.

The second one allows you to make your decisions. To decide, click on one of the buttons present on the screen.

The third one reminds you of the decisions taken in the previous periods.

\section{Example - Assume that X earns an endowment of 30 .}

All the participants are informed about the endowments $X$ earns. A period begins.

A table is randomly selected, for instance the table on the right. It is disclosed to $X$ and $Y$.

The player $Y$ offers a transfer to $X$. As the period is ongoing according to the right hand table, the maximum transfer is 70 .

We suppose $Y$ is proposing 15.

$X$ is informed about the proposed amount of the transfer. We suppose, for instance, he accepts it and then makes his decision:

\begin{tabular}{|c|c|c|c|}
\hline IF A IS CHOSEN & IF B IS CHOSE & & IF C IS CHOSEN \\
\hline $\mathrm{X}$ 's payoff is: $30+15=\mathbf{4 5}$ & 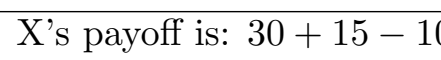 & & yoff is: $30+15-10$ \\
\hline Y's payoff is: $40-15$ & Y's payoff is: $40-15$ & $=25$ & Y's payoff is: $70-15$ \\
\hline
\end{tabular}

\section{PAYMENT OF YOUR EARNINGS}

At the end of the experiment, we will add up your payoffs. This amount will be converted into $€$ based on an exchange rate of 100 points $=1 €$. You will be paid this amount in cash at the end of the experiment. A lump sum of $3 €$ will be added to this amount.

If you have any questions, raise your hand, and someone will come to you. You are requested not to communicate with other participants during the experiment. If you do so, you will be excluded without payment of your potential gains. We would greatly appreciate your cooperation in this matter.

\section{Many thanks for your participation.}




\section{RULES FOR THE SECOND PHASE}

The second phase is composed of two parts, each part consisting of five periods. Groups and roles remain as during the first phase.

At the beginning of the second phase, a participant is added to your group. Ti is the participant Z. The participant $\mathrm{Z}$ involved in your group remains the same for the whole second phase.

\section{HOW EACH PERIOD IS CHANGED}

At the beginning of the each period, $\mathbf{Z}$ chooses $\mathbf{X}$ 's payoff. To do so, at the start of each period he chooses, at each period, between two possible payoffs. The two payoffs between which $\mathrm{Z}$ can choose are announced to all participants at the beginning of each period.

After this decision, all the group members are informed about Z's decision. Form this point, The period is the same as during the first phase. The table according to which the period will take place is randomly selected, with a 0.5 probability for each table. Only $\mathbf{X}$ and $\mathbf{Y}$ know which table was randomly chosen.

\begin{tabular}{|c|c|c|c|}
\hline X's decision & Cost for X & Z's Payoff & Y's Payoff \\
\hline $\mathrm{A}$ & 0 & 70 & 70 \\
\hline $\mathrm{B}$ & 10 & 100 & 70 \\
\hline $\mathrm{C}$ & 10 & 70 & 100 \\
\hline
\end{tabular}

\begin{tabular}{|c|c|c|c|}
\hline X's decision & Cost for X & Z's Payoff & Y's Payoff \\
\hline A & 0 & 40 & 40 \\
\hline B & 10 & 70 & 40 \\
\hline C & 10 & 40 & 70 \\
\hline
\end{tabular}

\begin{tabular}{|c|c|}
\hline Minimum transfer & 0 \\
\hline Maximum transfer & 100 \\
\hline
\end{tabular}

Left table(g)

\begin{tabular}{|l|c|}
\hline Minimum transfer & 0 \\
\hline Maximum transfer & 70 \\
\hline
\end{tabular}

Right table(d)

X then chooses between A, B or C. This choice affects X's payoffs, Y's payoffs but also Z's payoffs. For instance, if the left table is randomly chosen and $\mathrm{X}$ chooses the option $\mathrm{B}, \mathrm{X}$ bears a cost of 10 units deducted from his earnings for the period, $\mathrm{Y}$ earns 70 and $\mathrm{Z}$ earns 100 . $\mathrm{Y}$ is the only participant who knows X's decision.

To sum up, each period in the second phase is ongoing according to the following steps :

- 1st Stage: Y chooses X's endowment out of the two possible choices.

- 2nd Stage: A table is randomly selected according to a 0.5 probability. X and Y are informed of both the choice of table and the endowment chosen by $\mathrm{Z}$.

- 3rd Stage: Y offers a transfer to X, between 0 and 100 if the left table was selected and between 0 and 70 if the left table was selected.

- 4th Stage: X accepts or rejects the transfer.

- 5th Stage: X either accepts or rejects this transfer.

- 6th Stage: Y and Z earn the payoffs specified by X's decision.

- Y's net payoff equals this payoff minus the proposed transfer if accepted.

- Z's net payoff equals this payoff minus the payoff $Z$ chose for $X$.

- X's net payoff equals the endowment, plus the transfer if accepted, minus the cost of the decision. 
At the end of the period, your payoff and your net payoff for the current period appears on the screen.

\section{HOW EACH PART WILL UNFOLD}

The second phase includes two parts. The only change from one part to another are the two possible payoffs between which $\mathbf{Z}$ chooses. Those rules are announced to all the participants before the first period of each part.

At the end of the five periods, every participant begins a new part. Groups and roles remain the same during the two parts.

\section{Example - Assume that $\mathrm{Z}$ can choose between 15 and 30.}

All the participants are informed about the two possible earnings between which $Z$ chooses. A period begins.

A table is randomly selected, for instance the table on the right. It is disclosed to $X$ and $Y$.

Assume $Z$ chooses 30. $X$ and $Y$ are both informed of this decision.

The player $Y$ offers a transfer to $X$. As the period is ongoing according to the right hand table, the maximum transfer is 70 .

We suppose $Y$ is proposing 15.

$X$ is informed about the proposed amount of the transfer. We suppose, for instance, he accepts it and then makes his decision:

\begin{tabular}{|l|l|l|ll|}
\hline \multicolumn{2}{|c|}{ IF A IS CHOSEN } & \multicolumn{2}{|c|}{ IF B IS CHOSEN } & \multicolumn{2}{|c|}{ IF C IS CHOSEN } \\
\hline X's payoff is: $30+15=\mathbf{4 5}$ & X's payoff is: $30+15-10=\mathbf{3 5}$ & X's payoff is: $30+15-10$ & $=\mathbf{3 5}$ \\
Z's payoff is: $40-30=\mathbf{1 0}$ & Z's payoff is: $70-30$ & $=\mathbf{4 0}$ & Z's payoff is: $40-30$ & $=\mathbf{1 0}$ \\
Y's payoff is: $40-15=\mathbf{2 5}$ & Y's payoff is: $40-15$ & $=\mathbf{2 5}$ & Y's payoff is: $70-15$ & $=\mathbf{5 5}$ \\
\hline
\end{tabular}




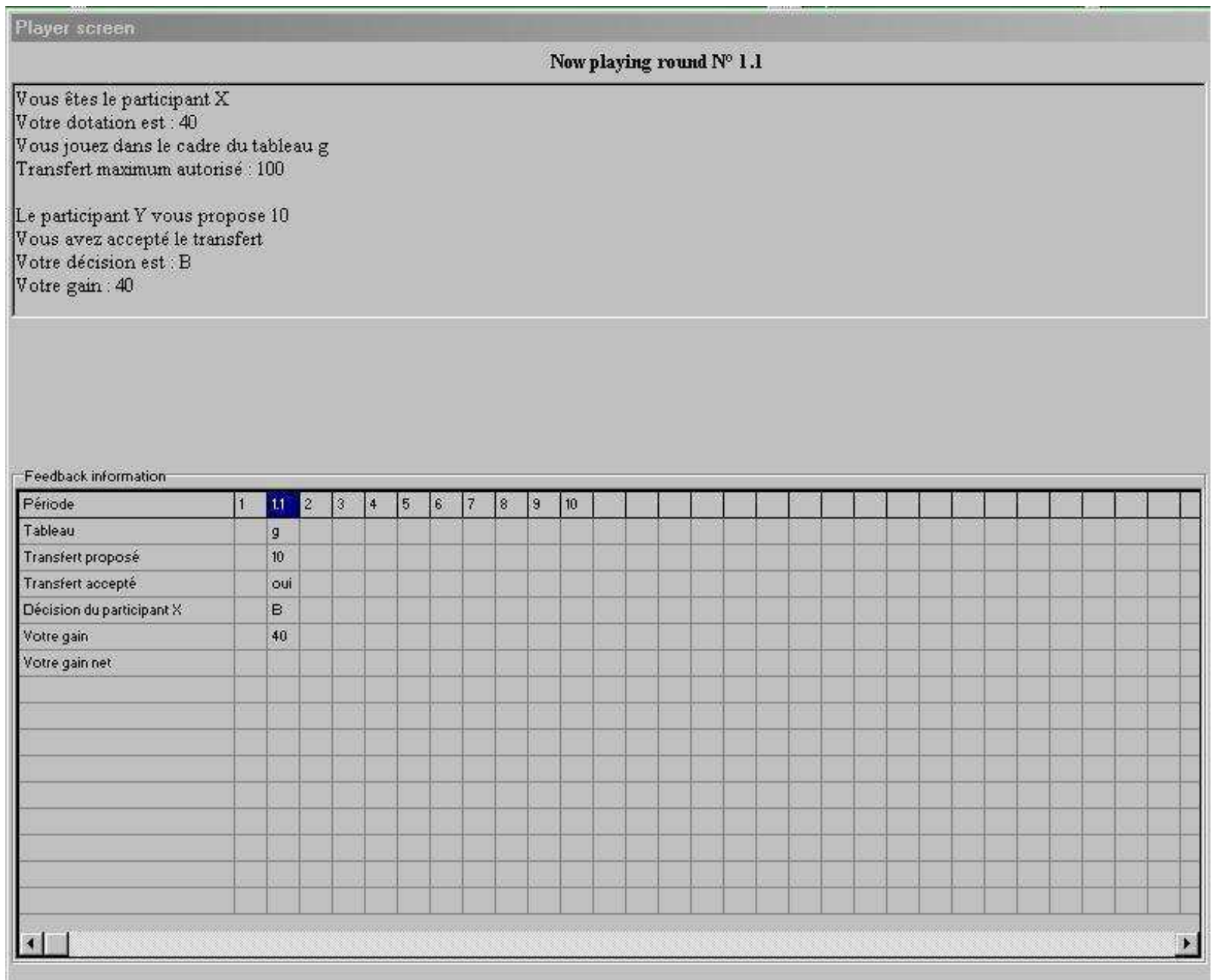

Figure 3: Agent sCREen display for CE 